\title{
A IMPORTÂNCIA DA FOTOGRAFIA JUDICIÁRIA NA PERÍCIA
}

\author{
José Lopes Zarzuela \\ Professor Assistente do Departamento de Medicina Forense \\ da Faculdade de Direito da Universidade de São Paulo \\ Perito Criminal aposentado do Instituto de Criminalística de São Paulo
}

\begin{abstract}
Resumo:
A fotografia judiciária constitui uma importante modalidade de levantamento do local do fato e não menos importante processo acessório para ilustrar as diversas espécies de perícias criminalísticas e médico-legais. A multiplicidade de técnicas fotográficas modernas dão um colorido especial aos laudos periciais evidenciando ângulos dificilmente descritos ou inadequadamente compreendidos por pessoas leigas em áreas técnicas. Com suas rígidas características, a fotografia judiciária revela as coisas exatamente como o perito as vê, dentro de um realismo, não raro, chocante.
\end{abstract}

\begin{abstract}
:
Judiciary photography is an important way to survey the place of the fact, and a no less important accessory to illustrate the several types of criminal and medico-legal expert examinations. The variety of modern photograpic techniques give a special color to expert examination reports, showing angles that are hard to describe or that would be misunderstood by lay people in technical areas. With its strict characteristics, judiciary photography shows things exactly as the expert sees them, so realistically as to become, not infrequently, shocking.
\end{abstract}

\section{Sumário:}

1. Conceito

2. Aspectos médico-legais criminalísticos da fotografia

3. Aspectos processuais penais da fotografia judiciária

4. Aplicações da fotografia judiciária

5. Técnicas fotográficas

6. Caracteres da fotografia judiciária

7. Tipos de fotografias judiciárias de interesse pericial

8. Bibliografia 


\section{Conceito}

Fotografia judiciária, também conhecida como fotografia técnica, fotografia forense e fotografia legal, constitui uma das modalidades de levantamento técnico-pericial do local do fato, bem como uma das espécies de reprodução do instrumento de crime, cadáver ou peça relacionada com a infração penal e com o irrelevante penal.

O conjunto de exames que são procedidos no instrumento do crime, na peça relacionada ou não com a infração penal ou no espaço físico onde se desenvolveu um evento de presumível ou de efetivo interesse judiciário, visando a apreciação, interpretação, perpetuação e legalização dos vestígios a fim de que possa o perito esclarecer a natureza da ocorrência constitui, na linguagem médico-legal criminalística, o levantamento técnico-pericial onde a fotografia judiciária representa um contingente de significativa importância na formação e fixação do convencimento da autoridade judiciária, do membro do Ministério Público, da autoridade policial e dos advogados que militam no foro criminal e cível.'

A análise do instrumento do crime, da mancha de sangue, da impressão papilar, do documento falsificado ou alterado, do local do fato, constituem exames de corpo de delito direto nos quais intervém a fotografia judiciária como precioso subsídio para complementar a descrição escrita do perito, uma vez que documenta, perpetua e autentica vestígios para que possam ser futuramente oferecidos como elementos probatórios e para assegurar-lhes juridicamente a idoneidade.

\section{Aspectos médico-legais criminalísticos da fotografia judiciária}

A fotografia tem na Medicina Legal e na Criminalística modernas aplicações bastante diversificadas, tornando-se desde há muito um meio objetivo de expressão de notória importância.

O levantamento fotográfico representa um complemento da déscrição escrita, residindo seu interesse na objetividade de documentar aspectos, não raro, complexos de serem traduzidos exclusivamente em palavras, particularmente, quando direcionados àqueles que não possuam cultura técnica especializada. 
As funções básicas da fotografia judiciária são as seguintes:

a fixa o estado das coisas enquanto necessário, isto é, perpetuar as condições em que se encontrava o local do fato, o instrumento do crime, a peça relacionada com a infração penal, a lesão pérfuro-contusa do cadáver, as manchas de sangue, o vestígio de impacto de projétil de arma de fogo em uma parede, a destruição do sistema de segurança de um cofre-forte ou da folha de uma porta, etc., como foram, objetivamente, apreciados pelo perito;

b - constituir forma elementar de evidenciar ao leigo, em assuntos técnico-científicos, circunstâncias ou aspectos relevantes, de difícil ou de complexa explicação;

c - ilustrar ângulos tecnicamente de interesse para o juiz de Direito, para o promotor público, para a autoridade policial e para o advogado;

d oferecer visão clara das lesões corporais apresentadas pela pessoa viva ou morta, dimensionando-as e quantificando-as, indicando sua localização anatômica, sua gravidade e esclarecendo serem tais lesões provocadoras, ou não, do êxito letal.

\section{Aspectos processuais penais da fotografia judiciária}

A expressão jurídica do interesse processual da fotografia judiciária encontra-se no Título VII Da Prova , Capítulo II - Do Exame de Corpo de Delito e das Pericias em Geral, arts. 164-170 do Código de Processo Penal vigente.

Assim uma breve exegese destes artigos nos permite esclarecer:

a o art. 164 do CPP refere-se à perinecroscopia, isto é, ao exame de encontro de cadáver no local do fato, devendo o perito providenciar que seja fotografado o cadáver, sempre que possível, na posição em que for encontrado. O legislador, com muita propriedade, empregou a expressão "sempre que possivel", pois há circunstâncias em que o cadáver não pode ser fotografado na posição em que se achava; considere-se casos de cadáveres soterrados, imersos no fundo de poços profundos ou no leito de rios ou lagos, etc. Nestas circunstâncias o perito não vai ao cadáver, e sim, providencia para que o cadáver venha a ele; 
b o art. 165 do CPP refere-se às lesões corporais encontradas no cadáver e também, inclusive, no vivo, os peritos quando possível juntarão ao laudo do exame provas fotográficas, etc.

Tanto no cadáver quanto na pessoa viva, a fotografia judiciária presta-se para ilustrar a natureza, tipo e número de lesões corporais, permitindo esclarecer o caráter do evento, se acidental ou delituoso;

c - o art. 166 do CPP refere-se a casos de dúvida sobre a identidade do cadáver exumado; além das clássicas técnicas de arcadas dentárias, osteométricas e dermatoglíficas, constitui importante subsídio a fotografia judiciária para conduzir ao levantamento da identidade do de cujus;

d - o art. 169 in fine do CPP refere-se à possibilidade dos laudos periciais do Instituto Médico-Legal, Instituto de Criminalística e Instituto de Identificação serem ilustrados com fotografias judiciárias, devidamente legendadas;

e o art. 170 in fine estabelece que os laudos periciais, sempre que conveniente para a instrução, deverão ser ilustrados com fotoampliações, fotorreduções, microfotografia, macrofotografia, para ilustrar materiais examinados em laboratórios como substâncias farmacodependentes, manchas de sangue, de sêmen, microfotografias de células provocadoras de doenças infectocontagiosas, etc.

\section{Aplicações da fotografia judiciária}

O local onde foi praticada a infração penal ou o irrelevante penal não irá permanecer inalterado indefinidamente; é o que sucede no encontro de cadáver, nos veículos colididos na via pública, no prédio incendiado, no bem imóvel furtado, etc. Os veículos acidentados não podem permanecer na via pública além do tempo necessário para que se proceda ao levantamento do local; o cadáver deverá ser removido para efeito de exames médico-legais e depois exumado ou cremado; o prédio incendiado deverá ser reconstruído ou arrazado para dar lugar a outro imóvel; os sistemas de segurança de um imóvel furtado deverão ser supridos por outros; em um homicídio no interior de um prédio são importantes as relações espaciais do cadáver, móveis, paredes, vias naturais de acesso ou saída ao compartimento onde foi encontrado o corpo do indivíduo; no 
caso de um furto qualificado por rompimento de obstáculos, é necessário para o perfeito enquadramento legal do fato a comprovação material da destruição do obstáculo que se interpunha ao ladrão para a subtração do bem alheio.

Em todos estes casos e em outros similares a fotografia judiciária fixa a situação e características exatamente como o perito as encontrou; além disto todos os vestígios são reproduzidos. Graças à fotografia judiciária, o perito abrevia as diligências realizadas no local do fato, descrevendo minuciosamente as particularidades do espaço físico onde se desenvolvera a ocorrência, as características do instrumento do crime, as peças, manchas, vestígios de arrastamento ou luta, de resistência, etc., fixando todo esse somatório de elementos com a exatidão indispensável da fotografia judiciária que independe da memória do perito e da concordância ou discordância das testemunhas. Além deste importante aspecto, é necessário lembrar que a fotografia técnica se presta para comprovar tanto a idoneidade quanto a inidoneidade do local do fato, por ocasião da chegada do perito ao mesmo.

As aplicações da fotografia legal são de largo espectro, tanto no local quanto nas peças, nos macro e microvestígios, nas falsificações documentais, nos enxertos de escritas, nas rasuras superficiais ou profundas, nos cadáveres de desconhecidos com o objetivo de auxiliar o reconhecimento por parentes ou conhecidos, evidenciar lesões no cadáver e no vivo e aspectos de relevante interesse durante a necropsia.

\section{Técnicas fotográficas}

Como é sabido, o olho humano só é sensível a uma estreita fração do espectro eletromagnético; as radiações ultravioletas e infravermelhas, que delimitam o campo visível do espectro, não são visíveis ao olho humano mas podem sensibilizar algumas emulsões fotográficas. Esta propriedade das radiações UV e IV sugere o emprego da fotografia técnica com filtros apropriados, particularmente nos cruzamentos de traços com escritos; fotografadas com luz negra, cédulas de papel-moeda podem revelar fraudes pela diferente fluorescência que apresentam em relação às cédulas legítimas. Quando determinadas características de um vestígio possuem exíguas dimensões de modo a dificultarem sua observação a olho nu, a microfotografia constitui a solução, 
como são os casos de fios de cabelo, fibras vegetais ou sintéticas, defeitos na estrutura de ligas metálicas, correspondência entre duas partes de um objeto partido, marcas de ferramentas, vestígios do biscoito dos pneumáticos de veículos em determinadas superfícies, etc.

As técnicas fotográficas empregadas contemporaneamente na Medicina Legal e na Criminalística são consideravelmente diversificadas, destacando-se a fotografia estereoscópica, a telefotografia, a fotografia com luz rasante, a microfotografia, a fotografia a cores, com luz UV e IV, etc.

Rudolph Archibald Reiss conclui sobre a finalidade da fotografia nos locais do fato: "permite à autoridade judiciária ter uma imagem exata do local do fato, fornecendo material apropriado para demonstraçôes elementares aos juizes de fato, advogados e representantes do Ministério Público durante o julgamento".

A imagem fotográfica pode exercer influência psicológica tanto sobre o acusado como sobre o juiz e os jurados. Pode revelar particularidades, às vezes despercebidas pelo perito, não raro valiosas para a identificação do responsável pela prática de uma infração penal.

\section{Caracteres da fotografia judiciária}

A fotografia para ser considerada como prova judiciária deverá necessariamente apresentar as seguintes características:

a - destituída de retoques. A fotografia retocada tem valor artístico, mas não técnico, pois a introdução de quaisquer modificações descaracteriza o valor técnico da fotografia, dando margem, inclusive, à fraude;

b - deve ser necessariamente legendada. A fotografia judiciária deve apresentar sumariamente explicações do que a imagem fotográfica mostra. O que a fotografia visualiza é perfeitamente compreensível ao perito que determinou a fixação da cena do local do fato, a natureza do instrumento do crime, as características da peça examinada, etc. Todavia, a fotografia em si não se mostra tĩo reveladora para aqueles que são leigos em assuntos técnicos, razão pela qual a legenda procura suprir tal deficiência;

c - deve ser, sempre que necessário, assinalada. Em alguns casos, a fotografia judiciária apresenta microvestígios, invisíveis a olhos leigos: razão pela 
qual deverão tais vestígios serem apontados, através de setas e explicados pela legenda;

d deve ser nítida e reproduzir exatamente o que o perito apreciou. A fotografia judiciária constitui a retina do cientista. Para a objetivação e demonstração dos fatos, a fotografia judiciária representa um dos mais engenhosos processos técnico-científicos, uma verdadeira "testemunha muda" que necessita ser executada sob determinadas condições: honestidade profissional e obediência de requisitos técnicos;

e - deve apresentar dimensões compatíveis com o conteúdo que exibe. A fotografia forense não apresenta dimensões padronizadas, pois, destinase a fixar desde um microvestígio até a fotografia de um local de dilatada área geográfica. Obviamente não se deveria esperar que uma mesma superfície se prestasse tanto para reproduzir um microvestígio como para representar uma colisão em cadeia envolvendo muitos veículos em uma rodovia;

f deve mostrar uma rigorosa correspondência entre cópia, negativo e objeto fotografado. Como o objeto da fotografia nem sempre poderá existir, como é o caso de um cadáver, é necessário no mínimo que seja mantido arquivo dos negativos, a fim de poder reproduzir-se a cópia ou positivo, quando preciso, dentro do prazo de prescrição, previsto em lei.

\section{Tipos de fotografias judiciárias de interesse pericial}

Como modalidades de levantamento acessório do local do fato ou como meio subsidiário no exame do instrumento do crime, da peça relacionada com a infração penal ou com o irrelevante penal, na evidenciação das lesões corporais tanto no vivo como no cadáver, na fixação das situações e posições finais de veículos acidentados, etc., há vários tipos de fotografias, entre as quais podem destacar-se as seguintes:

a fotografia geral é a que reproduz o local do fato de modo abrangente, circunscrevendo praticamente a totalidade dos vestígios dentro do interesse criminalístico. Este tipo de fotografia judiciária é empregada nos locais de acidentes de trânsito, de incêndio, de encontro de cadáver em locais abertos, etc.; 
b fotografia panorâmica é a que reproduz globalmente o local do fato quando este apresenta considerável área geográfica. A fotografia aérea, neste caso, permite uma amplitude muito grande ou se obtém uma série de fotografias gerais de setores do local que, depois de reunidas, permitem a visão do local in totum. Este tipo de fotografia judiciária é aplicável nos acidentes de trânsito em cadeia, isto é, nas colisões em tamponamento;

c - fotografia métrica de Bertillon é a que permite que se obtenham a reprodução de distâncias e dimensões dos objetos; a fotografia métrica aperfeiçoada é obtida com máquinas fotográficas métricas capazes de produzir clichês em cujas cópias se lêem diretamente as dimensões do objeto ou local fotografado;

d - fotografia de minúcias, inadequadamente denominada de "detalhes", é a que reproduz particularidades contidas no instrumento do crime, na peça de exame, na lesão corporal, no documento, na escrita exarada em um suporte, no local do fato, etc.;

e fotografia simétrica de Moisés Marx é a que reproduz as dimensões e características de locais internos. A máquina fotográfica é disposta sucessivamente nos quatro ângulos diedros do recinto, em posições rigorosamente simétricas; obtém-se, assim, as fotografias de cada uma das paredes e as cópias depois de reunidas e coladas em um cartão permitem reproduzir o local interno;

f - rebatimento fotográfico consiste na reprodução do solo, paredes e tetos de um local interno.

\section{Bibliografia}

ALMEIDA Jr., A., COSTA Jr., J.B. de O. Lições de medicina legal. $20^{\mathrm{a}}$ ed. São Paulo : Editora Nacional, 1991.

BRASIL. Leis, Decretos, etc. Código de processo penal. 26a ed. São Paulo : Saraiva, 1987.

DEL PICCHIA Fo, José, DEL PICCHIA, Celso Mauro Ribeiro. Tratado de documentoscopia: da falsidade documental. São Paulo : Leud, 1976.

KEHDY, Carlos. Manual de locais de crime. In: Coletânea "Acácio Nogueira". $2^{\mathfrak{a}}$ ed. São Paulo, 1959. 
MENDES, Lamartine Bizarro. A fotografia judiciária. [S.I.p., s.c.p., s.d.] O'HARA, Charles E., OSTERBURG, James W. de Janeiro : Fundo de Cultura, 1964. ZBINDEN, Karl. Criminalística: investigação criminal. Lisboa, 1957. 